\title{
Metacercariae of Strigeidae Parasitizing Amphibians of the Chaco Region in Argentina
}

\author{
MONIKA I. HAMANN, MARÍA V. FERNÁNDEZ and CYNTHYA E. GONZÁLEZ \\ Consejo Nacional de Investigaciones Científicas y Técnicas/CONICET, Centro de Ecología \\ Aplicada del Litoral/CECOAL, W 3400 AMD, Corrientes, Argentina \\ Manuscript received on January 12, 2018; accepted for publication on April 29, 2018
}

\begin{abstract}
How to cite: HAMANN MI, FERNÁNDEZ MV AND GONZÁLEZ CE. 2019. Metacercariae of Strigeidae Parasitizing Amphibians of the Chaco Region in Argentina. An Acad Bras Cienc 91: e20180044. DOI 10.1590/00013765201920180044 .

Abstract: The goal of the present study was to analyze the metacercariae found in adult amphibians collected in the Argentinean Chaco region. A total of 194 frogs, Leptodactylus chaquensis, Leptodactylus latinasus, and Lepidobatrachus laevis was examined for digeneans. Three different larval trematodes of the genus Strigea (Digenea, Strigeidae) were found infecting the liver, mesentery, body cavity, and muscle of frogs. These metacercariae are described and illustrated for the first time and provide new information on the composition of metacercariae in amphibians, thus contributing to the knowledge of larval trematodes biodiversity in the Neotropical region. We also present new information on the morphology and morphometry of strigeid metacercariae.
\end{abstract}

Key words: Trematoda, Metacercariae, Amphibian, Argentina.

\section{INTRODUCTION}

The study of metacercariae in amphibians is significant because these hosts transmit metacercariae to terrestrial vertebrates, which are potential final hosts where these larvae can complete their life cycle. The identification of these larvae is not trivial, once they have few morphological features with taxonomic value.

In Argentina, Hamann and Gonzáles (2009) have reported morphological and metric features of metacercaria species of the families Diplostomidae Poirier, 1886, Plagiorchiidae Lühe, 1901, Ophistogonimidae Freitas, 1956, and Echinostomatidae Poche, 1926 in Argentinean hosts.

Correspondence to: Monika Inés Hamann

E-mail: monika_hamann@yahoo.com

ORCid: https://orcid.org/0000-0001-6999-7417
However, metacercariae of the family Strigeidae Railliet, 1919 in amphibians of the Neotropical region have not yet been morphologically characterized or illustrated (see Lunaschi and Drago 2007). In this context, our aim is to describe the morphological and metric features of strigeid metacercaria species in naturally infected frogs from the Argentinean Chaco Region.

\section{MATERIALS AND METHODS}

A total of 194 adult frogs, Leptodactylus chaquensis, Leptodactylus latinasus, and Lepidobatrachus laevis was collected in 3 localities of Argentina (Table I). All adult specimens were killed using a chloroform $\left(\mathrm{CHCI}_{3}\right)$ solution. The present study is in accordance with all the regulations and ethical and legal considerations for the capture and use 
TABLE I

Strigeid metacercariae recorded in amphibian hosts from Argentinean Chaco region.

\begin{tabular}{|c|c|c|c|c|}
\hline $\begin{array}{l}\text { Metacercaria } \\
\text { (Voucher id ) }\end{array}$ & $\begin{array}{c}\text { Host } \\
\text { (Voucher id) }\end{array}$ & Site of infection & Locality & Date of collection \\
\hline $\begin{array}{l}\text { Strigea } \text { sp. } 1 \\
\text { (CECOAL } \\
11020101)\end{array}$ & $\begin{array}{l}\text { Lepidobatrachus } \\
\text { laevis (CECOAL } \\
\text { 5141) }\end{array}$ & $\begin{array}{l}\text { Mesentery } \\
\text { Body cavity } \\
\text { Muscle }\end{array}$ & $\begin{array}{l}\text { Ingeniero Juárez Formosa } \\
\text { Province } 23^{\circ} 54^{\prime} \mathrm{S}, 1^{\circ} 51^{\prime} \mathrm{W}\end{array}$ & Feb. 2011 \\
\hline $\begin{array}{l}\text { Strigea sp. } 2 \\
\text { (CECOAL } \\
11101914)\end{array}$ & $\begin{array}{l}\text { Leptodactylus } \\
\text { latinasus } \\
\text { (CECOAL 5142) }\end{array}$ & $\begin{array}{l}\text { Mesentery } \\
\text { Body cavity }\end{array}$ & $\begin{array}{c}\text { Taco Pozo } \\
\text { Chaco Province } 25^{\circ} 36^{\prime} \mathrm{S}, \\
3^{\circ} 15^{\prime} \mathrm{W}\end{array}$ & Oct. 2011 \\
\hline $\begin{array}{l}\text { Strigea sp. } 3 \\
\text { (CECOAL } \\
11020203)\end{array}$ & $\begin{array}{c}\text { Leptodactylus } \\
\text { chaquensis (CECOAL } \\
3858)\end{array}$ & Liver & $\begin{array}{c}\text { Corrientes } \\
\text { Corrientes Province } \\
27^{\circ} 40^{\prime} \mathrm{S}, 58^{\circ} 48^{\prime} \mathrm{W}\end{array}$ & $\begin{array}{c}\text { Feb. } 2011 \\
\text { Apr. } 2003 \\
\text { Jun. } 2002-2003 \\
\text { Oct. } 2002\end{array}$ \\
\hline
\end{tabular}

of animals established by the National Scientific and Technical Research Council of Argentina. The esophagus, stomach, gut, lungs, liver, kidneys, body cavity, musculature, integument, and brain were examined for parasites. Metacercariae were counted and isolated from host tissues and then removed from cysts by using preparation needles. They were studied either in vivo mounted in $0.6 \%$ saline solution or killed in hot distilled water, fixed in $70 \%$ ethyl alcohol, stained with hydrochloric carmine, and mounted in Canada balsam. Measurements are given in micrometers $(\mu \mathrm{m})$, and range (mean $\pm \mathrm{SD})$. Metacercariae were identified following Yamaguti (1975) and Niewiadomska et al. (2002). Photographs were taken with a Leica DFC 295 camera mounted on a Leica DM 2500 microscope, Leica Microsystems, Wetzlar, Germany. For examination using scanning electron microscopy (SEM), some specimens were dehydrated through an ethanol series, acetone, and ether. The specimens were gold-coated and examined using a Jeol 5800LV, Jeol, Tokyo, Japan. Representative specimens were deposited at the Helminthological Collection of the Centro de Ecología Aplicada del Litoral (CECOAL), Consejo Nacional de Investigaciones Científicas y Técnicas (CONICET), Corrientes, Argentina.

\section{RESULTS AND DISCUSSION}

Strigea sp. 1

Cyst (measurements based on 10 cysts): Tetracotyle cyst, egg-shaped, 760-1100 (949.5 \pm 115.9$)$ long $\mathrm{x}$ $540-650$ (594.0 \pm 37.5$)$ wide; cyst inner wall of parasite origin with a hyaline layer, covered by a radiated layer, surrounded by an elastic layer apparently formed by the intermediate host as a reaction against the parasite (Figures 1a, 2a). Larvae not easily released.

Metacercaria (measurements based on 10 excysted metacercariae): Larva tetracotyliform, body bipartite, division into fore and hindbody (Figure 1b), 380-535 (435.5 \pm 48.62$)$ in total length. Pseudosuckers cochleariform, posterolateral to oral sucker (Figure 2b). Forebode cup-shaped, 260-390 (306.0 \pm 37.5$) \times 204-288(240.9 \pm 23.4)$, with oblique aperture, minute tegumental spines, and ciliated papillae (Figure 2d, e). Oral sucker subterminal, 55-70 $(64.0 \pm 6.13)$ x 50-70 (63.5 \pm 8.25). Pharynx strongly muscular, 30-36 (32.4 \pm $2.76) \times 26-39(31.4 \pm 3.78)$; ratio pharynx length to oral sucker length 1:0.4-0.6. Ventral sucker, $60-84(70.2 \pm 8.6) \times 80-95(86.0 \pm 6.18)$. Sucker width ratio 1:1.1-1.7. Holdfast organ composed of 2 lobes, with tegumental spines (Figure 2c). Ventral 

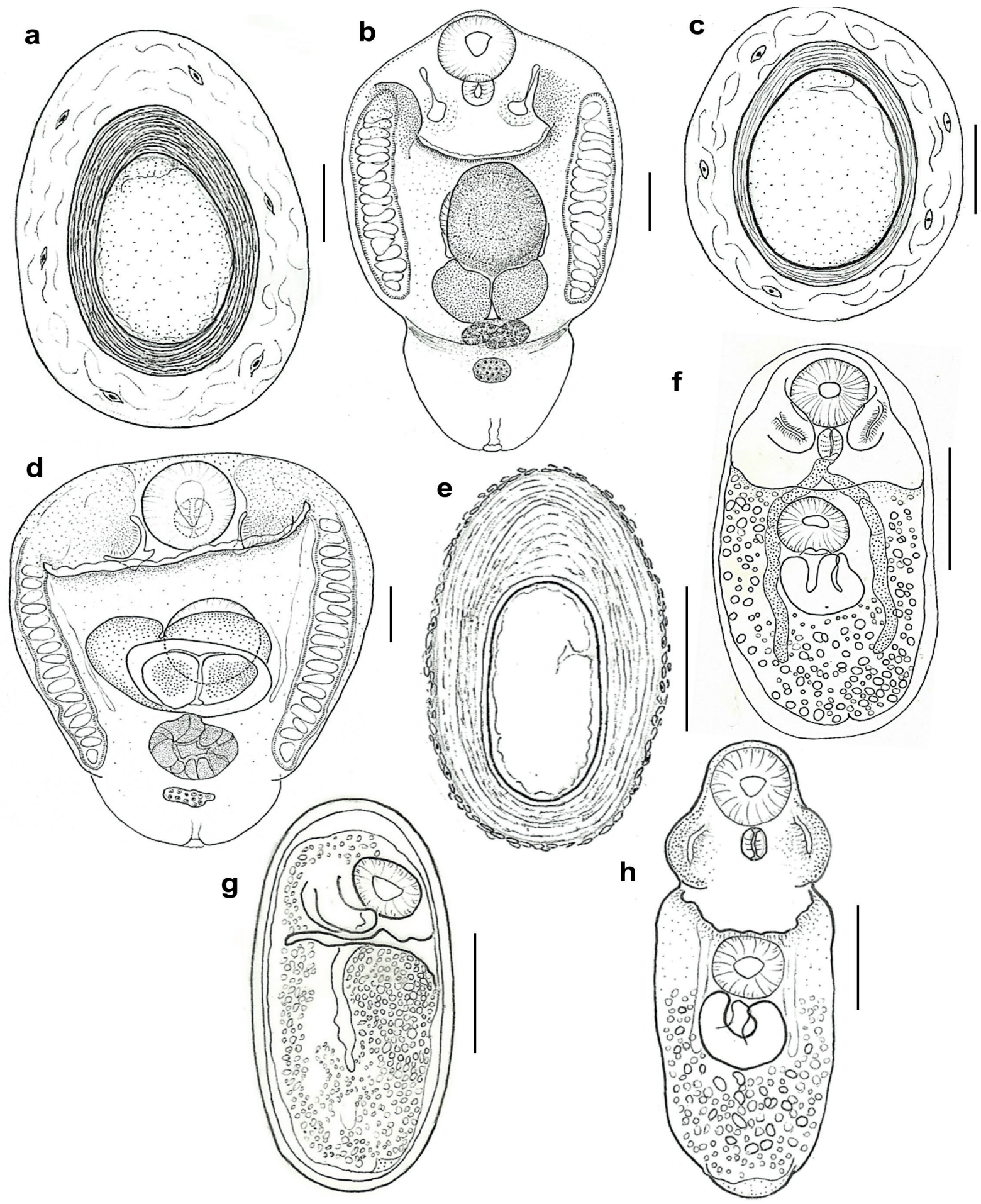

Figure 1 - Strigea sp. 1. (a) cyst; (b) whole-mount of excysted larva, ventral view. Strigea sp. 2. (c) cyst; (d) whole-mount of excysted larva, ventral view. Strigea sp. 3. (e) cyst; (f) larva encysted, ventral view; (g) larva encysted, lateral view; (h) wholemount of excysted larva, ventral view. Scale bars: $\mathbf{b}, \mathbf{d}, \mathbf{f}, \mathbf{g}, \mathbf{h}=50 \mu \mathrm{m} ; \mathbf{a}, \mathbf{c}, \mathbf{e}=150 \mu \mathrm{m}$. 


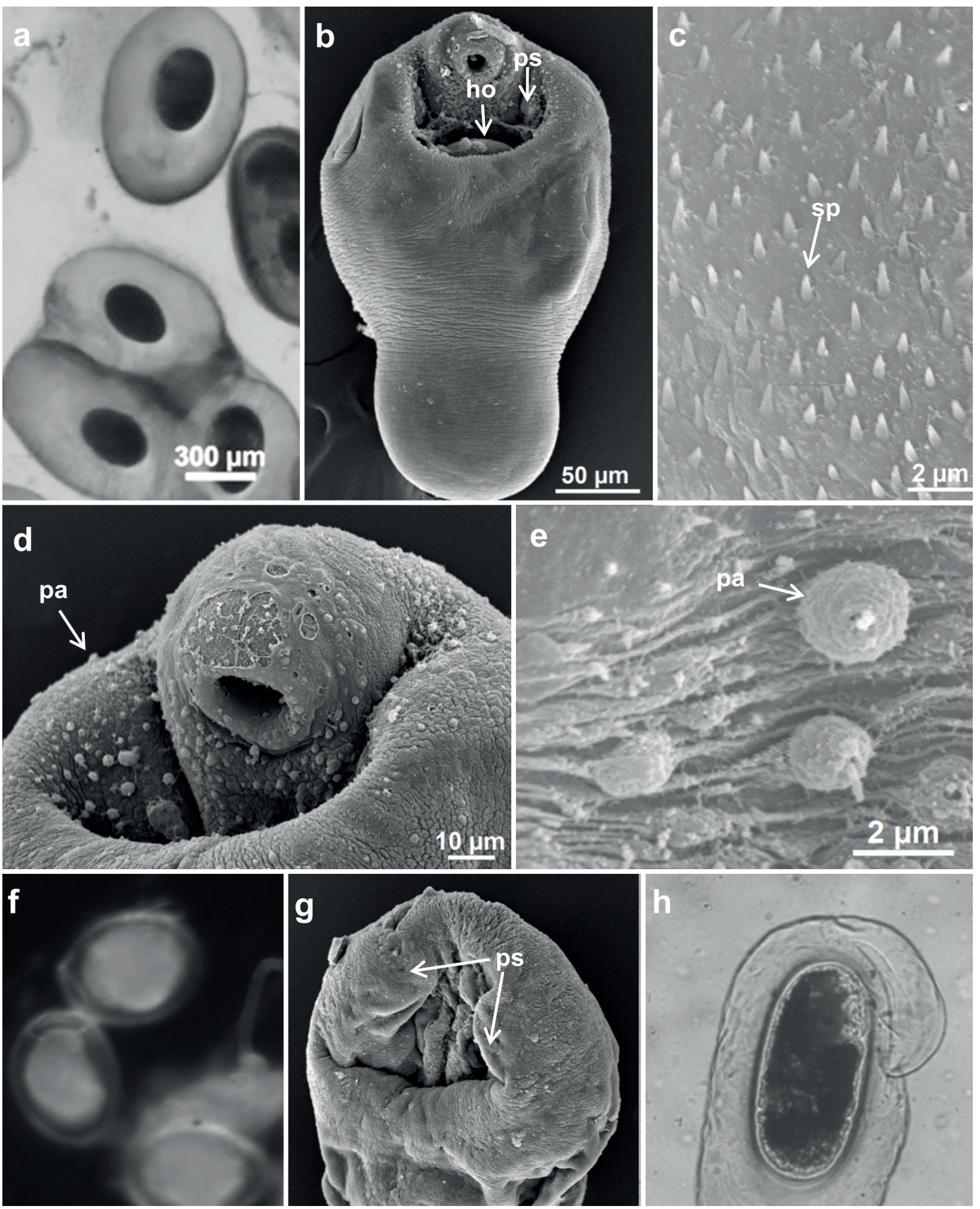

Figure 2 - Strigea sp. 1. (a) cysts; (b) whole-mount, ventral view; (c) tegumental spines of holdfast organ; (d) cephalic end, ventrolateral view; (e) cephalic region (note ciliated papillae). Strigea sp. 2. (f) cysts; (g) whole-mount, ventrolateral view. Strigea sp. 3. (h) cyst. Abbreviations: pa, papillae; ho, holdfast organ; ps, pseudosuckers; sp, spines. 
TABLE II

Morphology differences between strigeid metacercariae recorded in frogs from Chaco region, Argentina.

\begin{tabular}{cccc}
\hline & Strigea sp. 1 & Strigea sp. 2 & Strigea sp. 3 \\
\hline Forebody & Cup-shaped & Cup-shaped & Bell-shaped \\
Hindbody & Elongate & Wider than long & Smaller size \\
Holfast organ & Ventral lobe reaching to & Lobes not reaching & to anterior margin of \\
& anterior margin of forebody & Lobes not reaching to anterior margin & of forebody \\
Pseudosuckers & Posterolateral to oral sucker & Anterolateral edges & Anterolateral edges \\
Proteolyic gland & 2 conspicuous masses & 1 conspicuous mass & inconspicuous \\
Tetracotyle cyst & Cyst egg-shaped & Cyst oval shaped & Cyst elongated-oval shaped \\
\hline
\end{tabular}

lobe reaching the anterior margin of forebody, occasionally projected from opening. Proteolytic gland as 2 conspicuous masses at base of forebody. Hindbody cylindrical and curved dorsally, 100-155 $(129.5 \pm 18.8) \times 109-148(130.5 \pm 15.1)$. Genital primordia present in hindbody. Excretory ducts in the forebody, with the excretory bodies free in its canals (Figure 1b).

Prevalence and maximum intensity: One of 1 frog examined (100\%), 300 cysts approximately.

Strigea sp. 2

Cyst (measurements based on 10 cysts): Tetracotyle cyst oval, 400-500 (454.6 \pm 32.7$)$ long x 230-351 $(325.0 \pm 38.7)$ wide, cyst inner wall of parasite origin with a hyaline layer, covered by a radiated layer, surrounded by an elastic layer apparently formed by the intermediate host as a reaction against the parasite (Figures 1c, 2f). Larvae not easily released.

Metacercaria (measurements based on 10 excysted metacercariae): Larva tetracotyliform, body bipartite, division into fore and hindbody (Figure 1d), 335-480 (405.0 \pm 52.0$)$ in total length. Forebody cup-shaped, 220-380 (303.3 $\pm 52.4) \times 195-300(270.8 \pm 39.0)$, with a large opening and covered with minute tegumental spines. Pseudosuckers glandulo-muscular, on the anterolateral edges beside the oral sucker (Figure
$2 \mathrm{~g})$. Oral sucker subterminal, 50-83 (63.3 \pm 11.9$) \mathrm{x}$ 55-80 (61.1 \pm 8.1$)$. Pharynx strongly muscular, 25$45(38.0 \pm 9.2) \times 30-42(35.5 \pm 6.4)$; ratio pharynx length to oral sucker length 1:0.4-0.8. Ventral sucker, 63-81 (73.8 \pm 9.0) x 85-90 (86.8 \pm 2.5$)$. Sucker width ratio 1:1.1-1.5. Holdfast organ lobes not projecting from opening. Proteolytic gland compact and conspicuous, posterior to holdfast organ. Hindbody 55-100 (85.0 \pm 18.7$)$ x 80-165 $(137.0 \pm 32.9)$. Genital primordia, a small single mass, present in hindbody. Excretory ducts in the forebody, with the excretory bodies free in its canals (Figure 1d).

Prevalence and maximum intensity: One of 8 frogs examined (12.5\%), 198 cysts.

Strigea sp. 3

Cyst (measurements based on 10 cysts): Tetracotyle cyst, elongated-oval shaped, 340- 450 (377.8 \pm 34.4) long x 185-255 (227.2 \pm 16.9$)$ wide, cyst inner wall with a hyaline layer of parasite origin, covered by a radiated layer, surrounded by an elastic layer apparently formed by the intermediate host as a reaction against the parasite (Figures 1e, 2h). Larvae not easily released.

Metacercaria (measurements based on 10 metacercariae): Larva tetracotyliform; body bipartite, division into fore and hindbody. Forebody bell-shaped, 140-215 (170.5 \pm 18.6$) \times 60-75$ 
$(66.4 \pm 5.0)$, with a large opening (Figure $1 \mathrm{~h})$. Pseudosuckers well developed, glandulomuscular, on the anterolateral edges beside the oral sucker. Oral sucker subterminal, 20-35 $(26.2 \pm 4.5)$ x 2035 (27.2 \pm 4.3$)$. Pharynx strongly muscular, 14-15 $(14.7 \pm 0.6) \times 10-11(10.3 \pm 06)$; ratio pharynx length to oral sucker length 1:0.4-0.6. Ventral sucker, 20$32(24.5 \pm 4.4)$ x 23-35 (28.5 \pm 4.0$)$. Sucker width ratio 1:0.8-1.6. Holdfast organ lobes not projecting from opening. Proteolytic gland inconspicuous. Hindbody inconspicuous 10x30. Excretory ducts occupying the ventral, lateral and dorsal regions of the forebody (Figure 1f, g), with small spherical calcareous concretions free in its canals.

Prevalence and maximum intensity: Seven of 185 frogs examined (3.8\%), 500 cysts approximately.

Here we found 3 strigeid metacercariae in the Chaco region of Argentina. These metacercariae are added to the larvae previously described parasitizing different amphibians of Corrientes Province, Argentina (Hamann and González 2009), and are new records of metacercariae for the Chaco region. The main morphological differences between these 3 larvae are shown in Table II. We are aware that this study presents many gaps, which, hopefully, will be supplemented by future molecular analyses and life-cycle studies. Specifically, we contribute new information on morphological and metric data, when they are not known more than adult stage in most of the strigeid species recorded from Argentinean wild birds (see Drago and Lunaschi 2015).

\section{ACKNOWLEDGMENTS}

We thank the Secretary of Natural Resources of Chaco, Formosa and Corrientes Provinces, Argentina to authorize the capture of the toads for this research. Financial support was provided by CONICET of Argentina, through grant PIP 0111 to M. I. Hamann.

\section{AUTHOR CONTRIBUTIONS}

All authors collected the data and provided critical feedback and helped shape the research, analysis and manuscript.

\section{REFERENCES}

DRAGO FB AND LUNASCHI LI. 2015. Update of checklist of digenean parasites of wild birds from Argentina, with comments about the extent of their inventory. Neotrop Helminthol 9: 325-350.

HAMANN MI AND GONZÁLEZ CE. 2009. Larval digenetic trematodes in tadpoles of six amphibian species from Northeastern Argentina. J Parasitol 5: 623-628.

LUNASCHI L AND DRAGO FB. 2007 Checklist of digenean parasites of amphibians and reptiles from Argentina. Zootaxa 1476: 51-68.

NIEWIADOMSKA K. 2002. Superfamilia Diplostomoidea Poirier, 1886. In: Gibson DI et al. (Eds), Keys to the Trematoda: CABI, Publishing \& The Natural History Museum, London, UK, p. 159-166.

YAMAGUTI S. 1975. A synoptical review of life histories of digenetic trematodes of vertebrates, Tokyo, Japan: Keigaku Publishing Company, 590 p. 